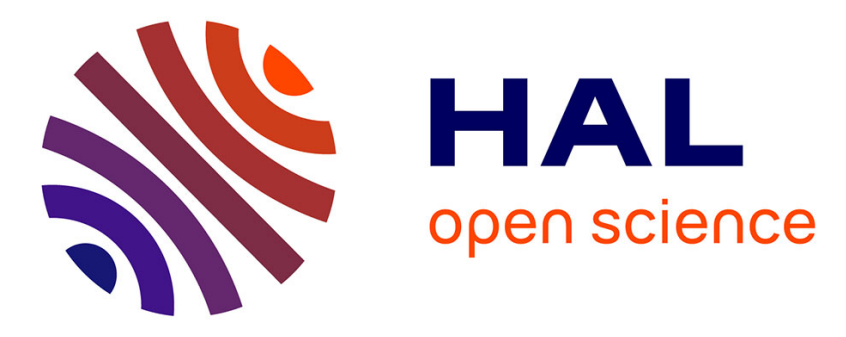

\title{
Comparison of Methods for the Estimation of Measurement Uncertainty for an Analytical Method for Sulphonamides
}

Marivil Dabalus Dabalus Islam, Mariana Schweikert Turcu, Andrew Cannavan

\section{- To cite this version:}

Marivil Dabalus Dabalus Islam, Mariana Schweikert Turcu, Andrew Cannavan. Comparison of Methods for the Estimation of Measurement Uncertainty for an Analytical Method for Sulphonamides. Food Additives and Contaminants, 2008, 25 (12), pp.1439-1450. 10.1080/02652030802189765 . hal00577397

\section{HAL Id: hal-00577397 \\ https://hal.science/hal-00577397}

Submitted on 17 Mar 2011

HAL is a multi-disciplinary open access archive for the deposit and dissemination of scientific research documents, whether they are published or not. The documents may come from teaching and research institutions in France or abroad, or from public or private research centers.
L'archive ouverte pluridisciplinaire HAL, est destinée au dépôt et à la diffusion de documents scientifiques de niveau recherche, publiés ou non, émanant des établissements d'enseignement et de recherche français ou étrangers, des laboratoires publics ou privés. 


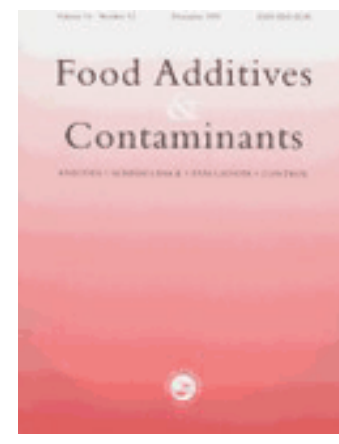

\section{Comparison of Methods for the Estimation of Measurement Uncertainty for an Analytical Method for Sulphonamides}

\begin{tabular}{|c|c|}
\hline Journal: & Food Additives and Contaminants \\
\hline Manuscript ID: & TFAC-2008-031.R1 \\
\hline Manuscript Type: & Special Issue \\
\hline $\begin{array}{r}\text { Date Submitted by the } \\
\text { Author: }\end{array}$ & 14-Apr-2008 \\
\hline Complete List of Authors: & $\begin{array}{l}\text { Dabalus Islam, Marivil; IAEA, Agriculture \& Biotechnology } \\
\text { Laboratory } \\
\text { Schweikert Turcu, Mariana; IAEA, Agriculture \& Biotechnology } \\
\text { Laboratory } \\
\text { Cannavan, Andrew; IAEA, Agriculture \& Biotechnology Laboratory }\end{array}$ \\
\hline Methods/Techniques: & Chromatography - HPLC, In-house validation \\
\hline Additives/Contaminants: & Veterinary drug residues - sulphonamides \\
\hline Food Types: & Meat \\
\hline
\end{tabular}


Marivil Dabalus Islam, Mariana Schweikert Turcu and *Andrew Cannavan.

Agrochemicals Unit, FAO/IAEA Agriculture and Biotechnology Laboratory, A-2444 Seibersdorf, Austria

*Corresponding author: Andrew Cannavan; Email address: a.cannavan@iaea.org 


\begin{abstract}
A simple and inexpensive liquid chromatographic method for the determination of seven sulphonamides in animal tissues was validated. The measurement uncertainty of the method was estimated using two approaches - a 'top-down' approach based on in-house validation data, which used either repeatability data or intra-laboratory reproducibility, and a 'bottom-up' approach, which included repeatability data from spiking experiments. The decision limits $(\mathrm{CC} \alpha)$ applied in the EU were calculated for comparison. The bottom-up approach was used to identify critical steps in the analytical procedure, which comprised extraction, concentration, hexane-wash and HPLC-UV analysis. Six replicates of porcine kidney were fortified at the MRL $\left(100 \mu \mathrm{g} \mathrm{kg}^{-1}\right)$ at three different stages of the analytical procedure, extraction, evaporation, and final wash/HPLC analysis, to provide repeatability data for each step. The uncertainties of the gravimetric and volumetric measurements were estimated and integrated in the calculation of the total combined uncertainties by the bottom-up approach. Estimates for systematic error components were included in both approaches. Combined uncertainty estimates for the seven compounds using the 'top-down' approach ranged from 7.9-12.5\% (using reproducibility) and from 5.4-9.5\% (using repeatability data) and from 5.1-9.0\% using the bottom-up approach. $\mathrm{CC} \alpha$ values ranged from 105.6-108.5 $\mu \mathrm{g} \mathrm{kg}^{-1}$. The major contributor to the combined uncertainty for each analyte was identified as the extraction step. Since there was no statistical difference between the uncertainty values obtained by either approach, the analyst would be justified in applying the 'top-down' estimation using method validation data, rather than performing additional experiments to obtain uncertainty data.
\end{abstract}

Keywords: uncertainty; top-down; bottom-up; sulphonamides; HPLC, decision limit 
The traditional method for estimating measurement uncertainty is by a 'bottom-up' approach, as described by EURACHEM/CITAC (Anon. 2000). Also referred to the as the uncertainty budget, this approach aims to estimate the individual contribution of every step and input to the analytical process to the overall uncertainty, and can be time consuming and difficult to apply to analytical methods for food contaminant regulation. This approach was developed by metrologists and physicists and proposed by ISO in the 'Guide to the expression of uncertainty in measurement' (GUM) (1993b; 1995), and subsequently adopted by EURACHEM for analytical chemistry. Another way of estimating the measurement uncertainty of analytical results is a more practical 'top-down' approach, as described by, inter alia, EURACHEM (Anon. 2000) and ISO (Anon. 2004) using the data obtained from inter-laboratory studies. However, this method is not ideal for application in residues laboratories, because it assumes that a standardized method is used in all laboratories, which is generally not true for residues analysis. One option is to apply a 'top-down' approach using the data generated by the in-house validation of the method. This approach is relatively simple, requires no extra practical work, and provides an initial uncertainty estimate that can be updated if necessary as further data becomes available through routine application of the method, for example from proficiency test results or repeated analysis of samples (Anon. 2007a).

Many laboratories, especially those in developing countries, have difficulty with the estimation of the measurement uncertainty associated with analytical methods (Cannavan. 2007; Cannavan and Elliott. 2004). This laboratory has had many requests for assistance in this area from developing 
country laboratories with which we are involved in capacity building projects. We chose to use a simple liquid-chromatographic multiresidue method for the determination of sulphonamides in animal tissues as a model to evaluate different practical approaches to the estimation of measurement uncertainty. The method had been developed and undergone preliminary validation in our laboratory as a suitable method for application in regulatory laboratories in resource-limited developing countries as well as in the developed world. The sulphonamides are an important class of antibacterial drugs widely used in veterinary practice and animal production. The European Union has set a maximum residue limit (MRL) of $100 \mu \mathrm{g} \mathrm{kg}^{-1}$ for the sulphonamides in a range of species and tissues (Anon. 1992), and Codex Alimentarius has adopted the same MRL for sulphamethazine in animal tissues (Anon. 2006). The method was validated in line with EU Commission Decision 2002/657/EC (Anon. 2002), including calculation of the decision limit $(\mathrm{CC} \alpha)$ and the detection capability $(\mathrm{CC} \beta)$. Two methods were used for the uncertainty estimation. The first, a 'bottom-up' approach, was based on the approach of Štěpán et al. (2004), which included some elements of a 'top-down' estimation in that it included repeatability data generated by fortification experiments at different stages of the method to estimate the contribution of each step to the overall uncertainty. The 'bottom-up' approach was also used to identify critical steps in the analytical procedure. The uncertainties associated with the gravimetric and volumetric measurements and analytical standards were estimated and integrated in the calculation of the total combined uncertainty using the 'bottom-up' approach. The second was a 'top-down' method, based on in-house validation data. The data were treated in two ways; as an overall intralaboratory reproducibility value and as three separate values generated from repeatability experiments performed on separate occasions and combined to produce an uncertainty estimate.

In both top-down and bottom-up approaches, it is considered that the uncertainty of each analytical step consists of random and systematic error components; hence estimates for both components were incorporated into the combined standard uncertainty.

The uncertainty estimates in this study were calculated and presented as relative standard uncertainties (\%), which permits their application over a range of values around and close to a reference point such as a maximum residue limit.

\section{Materials and methods}

Chemicals and reagents 


\section{Extraction and sample processing}

Portions $(3 \mathrm{~g})$ of the homogenized porcine kidney tissue were weighed into centrifuge tubes. If required, samples were spiked by the quantitative addition of standards in methanol, as described in the 'Method validation' and 'Experimental design for bottom-up uncertainty estimation' sections below, and allowed to stand at room temperature for at least 20 minutes. Hydrochloric acid $(0.1 \mathrm{M}, 500 \mu \mathrm{L})$ was added and each tube was vortex-mixed at full speed for 20 seconds. Anhydrous sodium sulphate $(2 \mathrm{~g})$ was then added whilst mixing. Ethyl acetate $(9 \mathrm{~mL})$ was added and each sample was homogenised immediately after addition using an Ultra-turrax homogeniser (IKA, Germany) at $9500 \mathrm{rpm}$ for 45 seconds. The resulting mixture was centrifuged $\left(650 \mathrm{~g}, 4{ }^{\circ} \mathrm{C}\right.$, 10 minutes). An aliquot (6 mL) of the supernatant was transferred into a conical test tube and evaporated to dryness using a Turbo-Vap (Zymark, Hopkinton, MA, USA) at $55{ }^{\circ} \mathrm{C}$ under a stream of nitrogen. The residue was reconstituted in methanol $(100 \mu \mathrm{L})$, glacial acetic acid (40 $\mu \mathrm{L})$ and water $(360 \mu \mathrm{L})$ with vortex mixing at each addition. The extract was washed with $2 \mathrm{~mL}$ of n-hexane by vortex mixing at low speed (low speed mixing avoided emulsion formation). The aqueous layer was transferred into an auto-sampler vial for HPLC-UV analysis. 


\section{High Performance Liquid Chromatography and data processing}

Chromatography was performed using a Dionex (Sunnyvale, CA, USA) system equipped with automated sample injector (ASI-100), photodiode array detector (PDA-100), binary pumps (P680), degassing system (DG-1210) and thermostatted column compartment (TCC-100).

A post-column derivatization apparatus was manually assembled using a $5 \mathrm{~m}$ x $0.5 \mathrm{~mm}$ i.d. coil of peek tubing (VICI International) and connected to a post-column pump and the analytical column via a zero dead-volume T-piece. The outlet of the reaction coil was connected to the detector. A Luna C18(2) $250 \times 4.6 \mathrm{~mm} \times 5 \mu \mathrm{m}$ column with a C18, 4 × $3 \mathrm{~mm}$ guard column (Phenomenex, Macclesfield, Cheshire, UK) was used for chromatographic separations. The injection volume was $50 \mu \mathrm{L}$. The column was maintained at $25^{\circ} \mathrm{C}$ and the post-column coil was at ambient temperature. The UV detector wavelength was set to $450 \mathrm{~nm}$.

A pre-mixed mobile phase comprising methanol/acetonitrile/glacial acetic acid/water $(10 / 6.5 / 1.5 / 82, \mathrm{v} / \mathrm{v} / \mathrm{v} / \mathrm{v})$ was pumped at a flow rate of $1.2 \mathrm{~mL} \mathrm{~min}^{-1}$ in isocratic mode for a total run time of 21 minutes. A derivatizing solution containing p-dimethylaminobenzaldehyde (1.5 g) in a mixture of methanol $(30 \mathrm{~mL})$, water $(20 \mathrm{~mL})$ and glacial acetic acid $(50 \mathrm{~mL})$ was delivered by the post-column pump at a constant flow rate of $0.5 \mathrm{~mL} \mathrm{~min}^{-1}$. The mobile phase and derivatising solution were filtered by vacuum through a $0.45 \mu \mathrm{m}$ HVLP filter (Phenomenex) before use.

Calibration curves were constructed using five concentrations of mixed sulphonamide standard, plus one 'zero'standard, covering the range required.

Chromeleon software (version 6.5 SP2 Build 968) was used to control all instrument conditions and for processing of the chromatographic data.

\section{Method Validation}

The trueness and precision of the analytical method were measured by the analysis of six negative porcine kidney samples fortified with each of the sulphonamides at three concentrations $(50,100$ and $150 \mu \mathrm{g} \mathrm{kg}^{-1}$, equivalent to $0.5,1.0$ and 1.5 times the Codex or EU MRL) on three separate occasions. The intra-laboratory reproducibility was checked by a second operator on a single occasion using HPLC equipment of similar specifications. The ruggedness of the method was evaluated by introducing minor alterations to seven variables in the extraction procedure and testing method recovery and repeatability against the nominal method. The variables selected 


\section{Experimental design for bottom-up uncertainty estimation}

Eighteen replicates of homogenized negative porcine kidney tissue were weighed into centrifuge tubes as described above. Six replicates were fortified with the analytes at $100 \mu \mathrm{g} \mathrm{kg}^{-1}$ at three stages of the analytical method, as described below:

\section{Fortification 1 (F1)}

Intermediate mixed sulphonamide standard $\left(10 \mu \mathrm{g} \mathrm{ml}^{-1}, 30 \mu \mathrm{L}\right)$ was added to each of six portions ( $3 \mathrm{~g}$ ) of homogenized negative porcine kidney in centrifuge tubes prior to the extraction step. The spiked samples were mixed briefly and allowed to stand for 20 minutes before commencing the extraction procedure.

\section{Fortification 2 (F2)}

Aliquots $(6 \mathrm{~mL})$ of the supernatants obtained after the extraction and centrifugation of six negative control samples were transferred into conical test tubes and spiked with mixed sulphonamide standard $\left(10 \mu \mathrm{g} \mathrm{ml}^{-1}, 20 \mu \mathrm{L}\right)$ prior to the evaporation step. The succeeding steps of the procedure were completed as described above.

\section{Fortification 3 (F3)}

After evaporation of the supernatant from six of the negative control samples, mixed sulphonamide standard $\left(10 \mu \mathrm{g} \mathrm{ml}^{-1}, 20 \mu \mathrm{L}\right)$ was added. The sample was reconstituted as described above, but using $80 \mu \mathrm{L}$ rather than $100 \mu \mathrm{L}$ methanol, and the final hexane wash step and HPLC analysis were completed. 


\section{Results and discussion}

\section{Method validation}

Typical chromatograms for a negative kidney sample, a mixed sulphonamide standard equivalent to $100 \mu \mathrm{g} \mathrm{kg}^{-1}$ and a negative kidney fortified at $100 \mu \mathrm{g} \mathrm{kg}^{-1}$ are presented in Figure 1 . The chromatograms are free from interference at the retention times of the analytes. Matrix-matched calibration standards were compared with standards prepared in mobile phase and no differences were observed in the calibration curves, so solvent standards were used thereafter. The method was validated for seven sulphonamides commonly used in veterinary medicine, but was shown to be suitable for the quantitative analysis of a range of sulphonamides, with some alterations to the mobile phase and the use of gradient elution for some compounds (data not presented). The simple isocratic method for seven compounds was chosen as a model for the measurement uncertainty study presented here.

Since certified reference materials for this matrix-analyte combination were unavailable, the trueness and precision of the analytical method were measured by fortification of negative sample matrix, as described above. The results are summarised in Table 1. The precision for all analytes is within the ranges recommended by Commission Decision 2002/657/EC and by Codex CAC GL 16 (Anon. 1993c). Analyte recovery for this matrix ranged from $61.6 \%$ to $91.7 \%$, recoveries for sulphathiazole and sulphamethizole being somewhat lower than for the other compounds. The recoveries obtained are acceptable for a multiresidue analytical method. Higher recoveries for sulphathiazole and sulphamethizole may be achieved using adjusted pH (Koesukwiwat et al. 2007), multiple extraction stages or, for example, alternative extraction solvents/buffers in combination with solid phase extraction clean-up. However, a key objective in the development of this method was that the method should be inexpensive and simple, making it applicable in a range of laboratories in both developed and developing countries. The simple extraction and minimal clean-up, with specificity enhanced by post-column derivatization, achieves this.

The introduction of minor variations in the seven individual factors described in the "Method validation' section above caused no significant variation in repeatability or recovery, demonstrating the ruggedness of the method. The protocol employed for ruggedness testing, performing replicate analyses with variations in one factor at a time, was relatively labour intensive. An alternative method, recommended in Commission Decision 2002/657/EC, is to apply a fractional factorial design, as described by Youden and Steiner (1975). In this approach, 
The method is applied routinely in a separate laboratory for the post-screening quantification of sulphonamides under an EU National Surveillance Scheme. A comparison of the validation data between the laboratories and an evaluation of method performance with 'real' incurred samples is being prepared and will be published elsewhere.

\section{The “bottom-up" method}

The identification and estimation of all individual uncertainty components, even for a relatively simple method such as that described here, can be difficult and time consuming. The approach used in this study aimed to identify and quantify the significant contributing factors to overall 
uncertainty, whilst using repeatability data for three individual steps of the procedure to account for the many other minor contributors inherent in each of the steps. The main sources of uncertainty evaluated using repeatability data were the extraction, the evaporation step, and the final wash/HPLC determination (hereafter referred to as the HPLC step).

In both the 'bottom-up' and 'top-down' approaches, the uncertainty estimation was based on both random and systematic error components of each individual analytical step. Random error typically arises from unpredictable variations of influence quantities, which give rise to variation in the repeated observations of the measurand (Anon. 2000). The uncertainty of the mean due to random effects is represented here by the repeatability of analytical measurements at each of the 3 fortification stages, expressed as the percentage relative standard deviation (or coefficient of variation, $\mathrm{CV}$ ) of the arithmetic mean of replicate determinations of the analyte as shown in equation (1).

$$
r_{1 \rightarrow 3}=\frac{S}{\bar{X}} \times 100
$$

where: $\bar{X}=$ the arithmetic mean and $S$ is the standard deviation of repeated determinations $(n=6)$;

$r_{1 \rightarrow 3}=$ repeatability of analyte for each individual step; expressed as CV (\%).

The results generated by the samples fortified before the extraction step include the random errors of not only the extraction step, but also the subsequent evaporation and HPLC steps. The random error component of the uncertainty of the extraction step, $r_{E x}$, is therefore calculated using equation (2):

$$
r_{E x}(\%)=\left(r_{1}^{2}-r_{2}^{2}-r_{3}^{2}\right)^{1 / 2}
$$

where: $r_{1}$ represents the combined random error (repeatability) of all individual steps;

$r_{2}$ is the combined random error of evaporation and HPLC;

$r_{3}$ is the random error of the HPLC step.

Similarly, the random error of the evaporation step, $r_{\text {Evap }}$, is calculated using equation (3).

$$
r_{\text {Evap }}(\%)=\left(r_{2}^{2}-r_{3}^{2}\right)^{1 / 2}
$$

For the HPLC step the random error, $r_{H P L C}$, is represented by the repeatability of the replicates fortified at the final stage of the method. 


$$
\begin{aligned}
& u(R)_{1 \rightarrow 3}=\frac{0.5 \times\left(100-R_{1 \rightarrow 3}\right)}{(3)^{1 / 2}} \ldots \ldots \ldots \ldots \ldots \ldots \ldots \ldots \ldots \ldots \ldots \ldots \ldots \ldots \ldots \ldots \ldots \ldots \ldots \ldots \ldots \ldots \ldots \\
& R_{1 \rightarrow 3}= \\
& u(R)_{1 \rightarrow 3}
\end{aligned}
$$

The systematic component of the uncertainty associated with the individual analytical steps is estimated using equations (5), (6) and (7):

For the extraction step

$$
u(R)_{E x}=\left(u(R)_{1}^{2}-u(R)_{2}^{2}-u(R)_{3}^{2}\right)^{1 / 2}
$$

For the evaporation step

$$
u(R)_{\text {Evap }}=\left(u(R)_{2}^{2}-u(R)_{3}^{2}\right)^{1 / 2}
$$

For the HPLC step

$$
u(R)_{H P L C}=\left(u(R)_{3}^{2}\right)^{1 / 2}=u(R)_{3}
$$

where: $u(R)_{1}=$ the systematic uncertainty component of all three steps combined;

$u(R)_{2}=$ systematic uncertainty component of evaporation and HPLC; $u(R)_{3}=$ systematic uncertainty component of the final wash/HPLC step.

The estimated uncertainties associated with the recovery for each analyte at each of the three steps evaluated are presented in Table 4.

\section{Other sources of uncertainty}




\section{Uncertainty of weighing}

As in the above estimation of uncertainty for individual analytical steps, both the random error and systematic error components were considered in this process. The random uncertainty of the balance, $r_{b a l}$, was determined using equation (8):

$$
r_{b a l}(\%)=\frac{S_{w}}{m_{s t d}} \times 100
$$

where: $S_{w}$ is the standard deviation of repeated weighings of a $25 \mathrm{mg}$ calibration weight $(n=6)$;

$m_{s t d}$ is the mass of analytical standard used for preparation of stock solution $(m=25 \mathrm{mg})$.

A systematic error component may be introduced due to, for example, preparation of a stock analytical standard solution when the actual amount of the standard material weighed is somewhere within the balance's stated tolerance, resulting in a bias in analytical results. This factor was estimated using the tolerance interval, $a( \pm 0.05 \mathrm{mg})$, declared in the calibration certificate and substituted in equation (9). A rectangular distribution is assumed.

$$
\sigma_{b a l}(\%)=\frac{a}{m_{s t d} \times(3)^{1 / 2}} \times 100
$$

\section{Uncertainty of dilution}

The random uncertainty of dilution, $r_{d i l}$, was determined using equation (10):

$$
r_{d i l}(\%)=\frac{S_{f f}}{m_{f f}-m_{e f}} \times 100
$$

where: $S_{f f}$ is the standard deviation of repeated weighings of the volumetric flask filled with methanol $(n=6, V=25 \mathrm{~mL})$;

$m_{f f}$ is the average weight of the volumetric flask filled with methanol;

$m_{e f}$ is the average weight of the empty volumetric flask.

Using the confidence interval, $b$, specified by the supplier of the volumetric flask $( \pm 0.04 \mathrm{~mL})$, the systematic error component was calculated using equation (11):

$$
\sigma_{d i l}(\%)=\frac{b}{V \times(3)^{1 / 2}} \times 100
$$

where: $V$ is the volume of volumetric flask $(25 \mathrm{~mL})$.

Uncertainty of standard purity \& calibration 
The stated purity of each analytical standard was taken into account when preparing standard solutions. It was assumed that uncertainty due to both standard purity and calibration non-linearity was negligible.

\section{Calculation of combined relative standard uncertainty}

The combined uncertainty of both random and systematic error components associated with extraction, evaporation, HPLC, weighing and, dilution was calculated using equations (12-16):

$$
\begin{aligned}
& u_{c \text { Ex }}(\%)=\left(r_{E x}^{2}+u(R)_{E x}^{2}\right)^{1 / 2} \\
& u_{c \text { Evap }}(\%)=\left(r_{\text {Evap }}^{2}+u(R)_{\text {Evap }}^{2}\right)^{1 / 2} \\
& u_{c \text { HPLC }}(\%)=\left(r_{H P L C}^{2}+u(R)_{H P L C}^{2}\right)^{1 / 2} \\
& u_{c b a l}(\%)=\left(r_{\text {bal }}^{2}+\sigma_{\text {bal }}(\%)\right)^{1 / 2} \\
& u_{c \text { dil }}(\%)=\left(r_{\text {dil }}^{2}+\sigma_{\text {dil }}(\%)\right)^{1 / 2}
\end{aligned}
$$

The combined uncertainty associated with the preparation of stock standard was calculated by integrating the uncertainty of weighing and dilution of the standard using equation (17):

$$
u_{c S t d}(\%)=\left(u_{c b a l}^{2}+u_{c d i l}^{2}\right)^{1 / 2}
$$

Using the values calculated for each of the above factors, the combined standard uncertainty, $u_{c}(\%)$, associated with the method was calculated using equation (18):

$$
u_{c}(\%)=\left(u_{c E x}^{2}+u_{c E v a p}^{2}+u_{c H P L C}^{2}+u_{c S t d}^{2}\right)^{1 / 2}
$$

As shown in Table 5, the combined relative standard uncertainties, estimated by the 'bottom-up' method, ranged from $5.1 \%$ to $9.0 \%$ for the seven analytes.

The individual contribution of each of the parameters investigated to the combined uncertainty of the method for each of the seven sulphonamides is illustrated in Figure 2. The contribution of the extraction step to the combined uncertainty was higher than the other steps in the method for six of the seven analytes. The combined uncertainty arising from weighing and dilution of the analytical standard is minor compared to the uncertainty due to the major stages of the analytical procedure. Components of uncertainty that do not contribute significantly to the total uncertainty of the test result can be neglected (Anon. 2000). 


\section{The 'top-down' method'}

\section{Intra-laboratory reproducibility (top-down method 1)}

The intra-laboratory reproducibility data for the method were used in the estimation of the uncertainty by the 'top-down' method. As for the 'bottom-up' method, both random and systematic error components were considered in the calculations. The overall reproducibility for all four days at all fortification levels for each analyte (random error, $r_{a v e}$ ), expressed as relative standard deviation, was taken from Table 1. The uncertainty of recovery (systematic error, $u(R)$ ) was calculated using equation (19):

$$
u(R)_{\text {ave }}=\frac{0.5 \times\left(100-R_{\text {ave }}\right)}{(3)^{1 / 2}}
$$

where: $u(R)_{a v e}$ is uncertainty of mean recovery for all occasions;

$R_{\text {ave }}$ is mean recovery of analyte obtained for all occasions.

The combined uncertainty is represented by equation (20):

$u_{\text {cave }}(\%)=\left(r_{\text {ave }}^{2}+(R)_{\text {ave }}^{2}\right)^{1 / 2}$

Table 6 shows the two components and the combined uncertainty values for each analyte using the 'top-down' approach.

This approach is in line with that accepted in the EU. Although measurement uncertainty is not explicitly mentioned in Commission Decision 2002/657/EC, the guidelines for implementation of the Decision (Anon. 2004b) specify that, when all relevant influencing factors are taken into account, including uncertainty of recovery, and recovery-corrected data are used, the intralaboratory reproducibility of a method can be regarded as a good estimate of combined uncertainty. Since the reproducibility data were obtained using recovery data, the systematic error component, $u(R)$, fulfils the requirement for the use of recovery-corrected data.

\section{Repeatability data on three occasions (top-down method 2)}

The repeatability data $\left(r_{o 1 \rightarrow 03}\right)$, expressed as relative standard deviations, for six replicates of negative matrix spiked at $100 \mu \mathrm{g} \mathrm{kg}^{-1}$ on three separate days (day 1-3) were used (Table 1). The uncertainty of recovery (systematic error, $u(R)$ ) was calculated using equation (21):

$$
u(R)_{o 1 \rightarrow o 3}=\frac{0.5 \times\left(100-R_{o 1 \rightarrow o 3}\right)}{(3)^{1 / 2}}
$$

where: $\quad r_{o 1 \rightarrow o 3}$ represents repeatability of analyte obtained for each occasion; 


$$
\begin{aligned}
& u(R)_{o 1 \rightarrow o 3} \text { is the uncertainty of recovery for each occasion; } \\
& R_{o 1 \rightarrow o 3} \text { is recovery of analyte obtained for each occasion. }
\end{aligned}
$$

The combined uncertainty for each occasion was calculated using equation (22):

$u_{c}(\%)_{o 1 \rightarrow 03}=\left(r_{o 1 \rightarrow 03}^{2}+u(R)_{o 1 \rightarrow o 3}^{2}\right)^{1 / 2}$

The quadratic mean, representing the combined uncertainty for each analyte, was calculated using equation (23):

$$
u_{c A v}(\%)=\left(\frac{u_{c o 1}^{2}+u_{c o 2}^{2}+u_{c o 3}^{2}}{3}\right)^{1 / 2}
$$

The combined uncertainties estimated using the 'top-down' method ranged from 8.0-12.6\% (method 1, using reproducibility) and 5.4-9.5\% (method 2, using repeatabilities) for the seven analytes. Comparison with the values produced using the 'bottom-up' method, which were between 5.1-9.0\%, (Table 8) showed that there was no significant difference between the estimates generated by the different approaches. The 'top-down' method using repeatability data can be easily applied where a method has undergone a preliminary validation, and can provide a realistic estimate of uncertainty which can be further elaborated upon additional validation.

\section{Compliance assessment}

In the field of veterinary drug residues, the result of an analysis is frequently used to decide whether it indicates compliance or non-compliance with a regulatory limit. One decision rule that is currently widely applied is that a result implies non-compliance with a limit if the measured value exceeds the limit by the expanded uncertainty (Anon. 2007b). The expanded uncertainty provides an interval which may be expected to encompass a large fraction of the distribution of values which could reasonably be attributed to the measurand and is obtained by multiplication of the combined standard uncertainty by a coverage factor. A coverage factor of 2 is generally recommended unless the combined uncertainty is based on statistical observations with less than about six degrees of freedom, in which case a greater factor may be required (Anon, 2000), but the factor is typically in the range $2-3$. In EU legislation a decision rule is applied that provides a low probability of false rejection, or a high confidence of correct rejection. Commission Decision 2002/657/EC specifies that the result of an analysis shall be considered non-compliant if the decision limit $(\mathrm{CC} \alpha)$ of the method is exceeded. The decision limit is based on the $\alpha$ error, which 
is the probability that the test sample is compliant, even though a non-compliant measurement has been obtained (false non-compliant decision), and is the concentration above which it can be decided with a statistical certainty of 1- $\alpha$ that the permitted limit has truly been exceeded. In the case of substances with established MRLs, such as the sulphonamides, $\alpha=5 \%$, whereas for compounds with no established permitted limit, $\alpha=1 \%$, giving an even lower probability of a false rejection. For the control of compliance, the measurement uncertainty is taken into account by applying the decision limit, CC $\alpha$. (Anon. 2004b). To ensure consistent regulation, it is of the utmost importance that both the decision rule to be applied and the method of calculating the critical value are fully specified and agreed by the regulating body or competent authority and the laboratory.

\section{Conclusions}

The analytical method described was validated using in-house performance-based criteria and was shown to be suitable for screening or for quantitative analysis of a range of sulphonamide drugs. By choosing the fortification levels for validation experiments in line with EU Commission Decision 2002/657/EC, the data produced to characterize the method in terms of precision and recovery could also be used to calculate values for $\mathrm{CC} \alpha$ and $\mathrm{CC} \beta$, in line with the requirements of the EU. The method is cheap, simple and rapid and is suitable for application in both developed and developing country regulatory laboratories.

The method was used as a model to compare two different approaches to the estimation of uncertainty. The 'bottom-up' method is a relatively comprehensive and exhaustive approach, which required more time and care in designing and performing experiments to provide additional data for the estimation. This approach does, however, enable the analyst to identify the critical stages of the method and is useful in method optimization or troubleshooting during development. The 'top-down' approach is much simpler and more cost-effective, using data from the method validation process. This would be especially relevant in situations where a laboratory wishes to validate an existing method (such as a Codex endorsed method, or a method from the literature) for routine use. Since there was no statistical difference between the uncertainty values obtained by either approach, for this analytical method the analyst would be justified in applying a 'topdown' estimation using method validation data, rather than performing additional experiments to obtain uncertainty data. However, the approach used for uncertainty estimation must always be agreed by the customer of the laboratory, and by any accrediting or certifying body. 


\section{References}

Anonymous. 1992. European Union Council Regulation 675/92 of 18 March 1992. Off. J. Eur. Commun. L73/8

Anonymous. 1993a. International Vocabulary of Basic and General Terms in Metrology. International Organization for Standardization.

Anonymous. 1993b. Guide to the Expression of Uncertainty in Measurement. International Organization for Standardization.

Anonymous. 1993c. CAC/GL 16-1993, Codex guidelines for the establishment of a regulatory programme for control of veterinary drug residues in foods. FAO/WHO Food Standards Codex Alimentarius.

Anonymous. 1995. Guide to the Expression of Uncertainty in Measurement 2nd edition. International Organization for Standardization.

Anonymous. 2000. Quantifying uncertainty in analytical measurement (Guide 4). EURACHEM/CITAC.

Anonymous. 2002. Commission Decision 2002/657/EC of 12 August 2002. Off. J. Eur. Commun. L221/8.

Anonymous. 2004a. ISO/TS 21748, Guidance for the use of repeatability, reproducibility and trueness estimates in measurement uncertainty estimation. International Organization for Standardization.

Anonymous. Guidelines for the implementation of Decision 2002/657/EC, Sanco/2004/2726rev2 [Internet]. 2004b. [cited 2008 Jan 17]. Available from: 
Anonymous. 2005. International Standard ISO/IEC 17025, Second edition, General requirements for the competence of testing and calibration laboratories. International Organization for Standardization.

Anonymous. Veterinary Drug Residues in Food, Maximum Residue Limits [Internet]. 2006. FAO/WHO Food Standards Codex Alimentarius; [cited 2008 Jan 25]. Available from: http://www.codexalimentarius.net/mrls/vetdrugs/jsp/vetd_q-e.jsp

Anonymous. 2007a. Quality control procedures for pesticide residue analysis in food and feed. Document $N^{\circ}$ SANCO/2007/3131 of $31^{\text {st }}$ October 2007.

Anonymous. 2007b. Use of uncertainty information in compliance assessment. EURACHEM/CITAC.

Cannavan A. 2007. Third world regulatory concerns and collaborative work to protect consumers and facilitate international trade. Paper presented at: Saskatoon International Validation Workshop for Regulatory Analysis of Residues in Food. SaskVal Workshop; June 11-13; Saskatoon SK Canada.

Cannavan A and Elliott CT. 2004. The implementation of veterinary drug residues monitoring programmes in developing countries. Paper presented at: Conference on Residues of Veterinary Drugs in Food. Proceedings of the Euroresidue V Conference; Noordwijkerhout, The Netherlands. $151-158$

Koesukwiwat U, Jayanta S and Leepipatpiboon N. 2007. Solid-phase extraction for multiresidue determination of sulfonamides, tetracyclines, and pyrimethamine in Bovine's milk. J. Chromatogr. A. 1149:102-111.

Štěpán R, Hajšlová J, Kocourek V and Tachá J. 2004. Uncertainties of gas chromatographic measurement of troublesome pesticide residues in apples employing conventional and mass spectrometric detectors. Analytica Chimica Acta. 520:245-255.

Yakkundi S, Cannavan A, Elliott CT, Lővgren T. and Kennedy DG. 2001. Development and validation of a method for the confirmation of nicarbazin in chicken liver and eggs using LC Electrospray MS-MS according to the revised EU criteria for veterinary drug residue analysis. Analyst. 126: 1985 - 1989.

Youden WJ and Steiner EH. 1975. Statistical manual of the AOAC - Association of Official Analytical Chemists, AOAC-I, Washington DC, 35. 
Table 1. Method validation data for porcine kidney at fortification levels equivalent to $0.5 \times$ MRL, MRL and $1.5 \times$ MRL.

\begin{tabular}{|c|c|c|c|c|c|c|c|c|c|}
\hline Occasion & $\begin{array}{l}\text { Conc'n } \\
\left(\mu \mathrm{g} \mathrm{kg}^{-1}\right)\end{array}$ & & SDZ & STZ & SPY & SMR & SMT & SMZ & SMP \\
\hline \multirow{6}{*}{$\begin{array}{l}\text { Day } 1 \\
\text { Operator } 1\end{array}$} & \multirow{2}{*}{50} & $\operatorname{Rec}(\%)$ & 84.3 & 73.7 & 83.3 & 84.3 & 81.0 & 74.3 & 80.3 \\
\hline & & CV (\%) & 4.8 & 3.2 & 2.5 & 4.6 & 4.1 & 3.6 & 4.3 \\
\hline & \multirow{2}{*}{100} & $\operatorname{Rec}(\%)$ & 81.5 & 71.8 & 82.3 & 84.5 & 83.7 & 73.0 & 79.0 \\
\hline & & $\mathrm{CV}(\%)$ & 1.7 & 1.0 & 1.5 & 2.2 & 1.2 & 2.1 & 1.4 \\
\hline & \multirow{2}{*}{150} & $\operatorname{Rec}(\%)$ & 79.1 & 68.3 & 79.1 & 80.0 & 81.0 & 70.9 & 76.5 \\
\hline & & CV (\%) & 7.1 & 7.3 & 6.2 & 7.0 & 6.7 & 6.6 & 7.1 \\
\hline \multirow{6}{*}{$\begin{array}{l}\text { Day } 2 \\
\text { Operator } 1\end{array}$} & \multirow{2}{*}{50} & $\operatorname{Rec}(\%)$ & 82.7 & 71.0 & 81.3 & 83.3 & 78.7 & 73.3 & 82.0 \\
\hline & & CV (\%) & 5.2 & 3.0 & 2.5 & 5.2 & 3.8 & 3.7 & 3.4 \\
\hline & \multirow{2}{*}{100} & $\operatorname{Rec}(\%)$ & 89.0 & 74.0 & 88.3 & 89.2 & 89.3 & 75.8 & 80.3 \\
\hline & & $\mathrm{CV}(\%)$ & 5.1 & 5.4 & 4.6 & 5.1 & 5.2 & 6.2 & 5.8 \\
\hline & \multirow{2}{*}{150} & $\operatorname{Rec}(\%)$ & 80.7 & 68.1 & 79.2 & 80.2 & 81.2 & 72.6 & 78.6 \\
\hline & & $\mathrm{CV}(\%)$ & 7.0 & 7.7 & 6.4 & 7.2 & 6.8 & 6.8 & 7.0 \\
\hline \multirow{6}{*}{$\begin{array}{l}\text { Day } 3 \\
\text { Operator } 1\end{array}$} & \multirow{2}{*}{50} & $\operatorname{Rec}(\%)$ & 74.7 & 62.0 & 76.0 & 76.0 & 79.0 & 61.7 & 73.3 \\
\hline & & $\mathrm{CV}(\%)$ & 7.9 & 9.1 & 8.8 & 10.7 & 8.6 & 7.8 & 7.8 \\
\hline & \multirow{2}{*}{100} & $\operatorname{Rec}(\%)$ & 78.8 & 65.8 & 79.7 & 80.7 & 82.2 & 63.3 & 75.7 \\
\hline & & $\mathrm{CV}(\%)$ & 2.9 & 2.6 & 3.0 & 3.6 & 3.2 & 4.6 & 4.0 \\
\hline & \multirow{2}{*}{150} & $\operatorname{Rec}(\%)$ & 77.2 & 64.7 & 77.2 & 78.2 & 80.0 & 62.3 & 73.6 \\
\hline & & $\mathrm{CV}(\%)$ & 3.5 & 3.1 & 3.3 & 3.1 & 3.6 & 5.0 & 3.2 \\
\hline \multirow{2}{*}{$\begin{array}{l}\text { Overall } \\
\text { Operator } 1\end{array}$} & \multirow{2}{*}{$\begin{array}{c}\text { All } \\
\text { levels }\end{array}$} & $\operatorname{Rec}(\%)$ & 80.9 & 68.8 & 80.7 & 81.8 & 81.8 & 69.7 & 77.7 \\
\hline & & $\mathrm{CV}(\%)$ & 5.0 & 4.7 & 4.3 & 5.4 & 4.8 & 5.2 & 4.9 \\
\hline \multirow{6}{*}{$\begin{array}{l}\text { Day } 4 \\
\text { Operator } 2\end{array}$} & \multirow{2}{*}{50} & Rec (\%) & 86.0 & 666.3 & 82.7 & 86.7 & $\begin{array}{l}91.7 \\
\end{array}$ & $\begin{array}{l}70.3 \\
\end{array}$ & 83.3 \\
\hline & & $\mathrm{CV}(\%)$ & 1.5 & 4.0 & 2.0 & 3.5 & 4.7 & 3.3 & 3.9 \\
\hline & \multirow{2}{*}{100} & $\operatorname{Rec}(\%)$ & 84.5 & 65.2 & 81.7 & 82.8 & 86.7 & 67.0 & 83.0 \\
\hline & & $\mathrm{CV}(\%)$ & 1.6 & 3.4 & 3.3 & 2.3 & 2.3 & 2.8 & 4.2 \\
\hline & \multirow{2}{*}{150} & $\operatorname{Rec}(\%)$ & 80.5 & 61.6 & 77.5 & 79.6 & 81.3 & 62.9 & 79.6 \\
\hline & & $\mathrm{CV}(\%)$ & 1.5 & 2.9 & 1.9 & 2.0 & 2.5 & 4.9 & 1.8 \\
\hline \multirow{2}{*}{$\begin{array}{l}\text { Overall } \\
\text { Operator } 2 \\
\end{array}$} & \multirow{2}{*}{$\begin{array}{c}\text { All } \\
\text { levels }\end{array}$} & $\operatorname{Rec}(\%)$ & 83.7 & 64.4 & 80.6 & 83.0 & 86.6 & 66.7 & 82.0 \\
\hline & & $\mathrm{CV}(\%)$ & 3.2 & 4.6 & 3.7 & 4.4 & 6.0 & 5.9 & 3.9 \\
\hline \multirow{2}{*}{ Overall } & & $\operatorname{Rec}(\%)$ & 81.6 & 67.7 & 80.7 & 82.1 & 83.0 & 69.0 & 78.8 \\
\hline & & $\mathrm{CV}(\%)$ & 6.4 & 7.5 & 5.6 & 6.5 & 6.5 & 8.7 & 6.1 \\
\hline
\end{tabular}

Note: Results are for 6 replicates at each level on each day. Overall results are for all levels on all days. 
Table 2. Decision limit $(\mathrm{CC} \alpha)$ and detection capability $(\mathrm{CC} \beta)$ values obtained for the seven sulphonamides

\begin{tabular}{lccccccc}
\hline & SDZ & STZ & SPY & SMR & SMT & SMZ & SMP \\
\hline $\mathrm{CC} \alpha\left(\mu \mathrm{g} \mathrm{kg}^{-1}\right)$ & 106.7 & 105.6 & 106.3 & 107.0 & 106.8 & 108.5 & 108.2 \\
$\mathrm{CC} \beta\left(\mu \mathrm{g} \mathrm{kg}^{-1}\right)$ & 113.2 & 112.7 & 113.4 & 114.4 & 114.2 & 119.0 & 114.8 \\
\hline
\end{tabular}


Table 3. Repeatabilities (random error) of individual analytical steps

\begin{tabular}{lcccccc}
\hline \multicolumn{1}{c}{ CV(\%) } & F1 & F2 & F3 & Extraction & Evaporation & HPLC \\
& $r_{1}$ & $r_{2}$ & $r_{3}$ & $r_{E x}$ & $r_{E v a p}$ & $\left.r_{H P L C=} r\right)$ \\
\hline Sulphadiazine & 5.2 & 3.5 & 2.0 & 3.3 & 2.9 & 2.0 \\
Sulphathiazole & 5.4 & 3.5 & 1.9 & 3.6 & 2.9 & 1.9 \\
Sulphapyridine & 4.6 & 3.8 & 1.8 & 1.9 & 3.3 & 1.8 \\
Sulphamerazine & 5.0 & 3.3 & 1.9 & 3.2 & 2.7 & 1.9 \\
Sulphamethazine & 5.3 & 3.2 & 2.3 & 3.5 & 2.2 & 2.3 \\
Sulphamethizole & 6.2 & 2.7 & 2.0 & 5.2 & 1.8 & 2.0 \\
S'methoxypyridazine & 5.7 & 4.5 & 3.3 & 1.2 & 3.1 & 3.3 \\
\hline
\end{tabular}


Table 4. Uncertainties of recoveries (systematic error) of individual analytical steps

\begin{tabular}{lrrrrrrrrc}
\hline & $\mathrm{F} 1$ & $\mathrm{~F} 2$ & $\mathrm{~F} 3$ & $\mathrm{~F} 1$ & $\mathrm{~F} 2$ & $\mathrm{~F} 3$ & Extraction & Evaporation & HPLC \\
\hline \multicolumn{1}{c}{$\mathrm{CV}(\%)$} & $R_{I}$ & \multicolumn{1}{c}{$R_{2}$} & \multicolumn{1}{c}{$R_{3}$} & $u(R)_{l}$ & $u(R)_{2}$ & $u(R)_{3}$ & $u(R)_{E x}$ & $u(R)_{E v a p}$ & $u(R)_{H P L C}$ \\
\hline Sulphadiazine & 89.0 & 97.5 & 101.5 & 3.18 & 0.72 & -0.43 & 3.06 & 0.58 & -0.43 \\
Sulphathiazole & 74.0 & 93.0 & 99.8 & 7.51 & 2.02 & 0.06 & 7.23 & 2.02 & 0.06 \\
Sulphapyridine & 88.3 & 97.8 & 101.2 & 3.38 & 0.64 & -0.35 & 3.30 & 0.53 & -0.35 \\
Sulphamerazine & 89.2 & 97.8 & 102.2 & 3.12 & 0.64 & -0.64 & 2.99 & 0.00 & -0.64 \\
Sulphamethazine & 89.3 & 97.2 & 101.7 & 3.09 & 0.81 & -0.49 & 2.94 & 0.64 & -0.49 \\
Sulphamethizole & 75.8 & 93.2 & 102.8 & 6.99 & 1.96 & -0.81 & 6.66 & 1.79 & -0.81 \\
S'methoxypyridazine & 80.3 & 88.2 & 94.5 & 5.69 & 3.41 & 1.59 & 4.77 & 3.01 & 1.59 \\
\hline
\end{tabular}


Table 5 Combined uncertainties of sulphonamide compounds by "bottom-up" method

\begin{tabular}{lcccccc}
\hline & $u_{c E x}(\%)$ & $u_{c E v a p}(\%)$ & $u_{c H P L C}(\%)$ & $u_{c B a l}(\%)$ & $u_{c D i l}(\%)$ & $u_{c}(\%)$ \\
\hline Sulphadiazine & 4.491 & 2.930 & 0.866 & 0.069 & 0.109 & 5.4 \\
Sulphathiazole & 8.096 & 3.567 & 0.110 & 0.067 & 0.109 & 8.8 \\
Sulphapyridine & 3.790 & 3.389 & 0.624 & 0.066 & 0.109 & 5.1 \\
Sulphamerazine & 4.406 & 2.698 & 1.207 & 0.066 & 0.109 & 5.3 \\
Sulphamethazine & 4.605 & 2.316 & 1.129 & 0.065 & 0.109 & 5.3 \\
Sulphamethizole & 8.453 & 2.548 & 1.617 & 0.065 & 0.109 & 9.0 \\
S'methoxypyridazine & 4.423 & 4.294 & 5.239 & 0.064 & 0.109 & 8.1 \\
\hline
\end{tabular}


Table 6. Systematic and random components and combined uncertainty of each sulphonamide by the "top-down" method

\begin{tabular}{lccc}
\hline & $r_{\text {ave }}(\%)$ & $u(R)_{\text {ave }}(\%)$ & $u_{c}(\%)$ \\
\hline Sulphadiazine & 7.0 & 5.3 & 8.3 \\
Sulphathiazole & 7.5 & 9.3 & 12.0 \\
Sulphapyridine & 6.2 & 5.6 & 7.9 \\
Sulphamerazine & 7.0 & 5.2 & 8.3 \\
Sulphamethazine & 6.1 & 4.9 & 8.2 \\
Sulphamethizole & 9.1 & 9.0 & 12.5 \\
S'methoxypyridazine & 6.1 & 6.1 & 8.6 \\
\hline
\end{tabular}


Table 7. Uncertainties of sulphonamide compounds by 'top-down' method 2, using repeatability data (Operator 1 ) for negative matrix spiked at $100 \mu \mathrm{g} \mathrm{kg}^{-1}$

\begin{tabular}{|c|c|c|c|c|c|c|c|c|c|c|c|c|c|}
\hline \multirow[b]{2}{*}{ Sulphonamides } & \multirow[b]{2}{*}{$\begin{array}{l}R F_{1} \\
(\%)\end{array}$} & \multicolumn{3}{|c|}{ Occasion 1} & \multicolumn{4}{|c|}{ Occasion 2} & \multicolumn{4}{|c|}{ Occasion 3} & \multirow[b]{2}{*}{$\begin{array}{l}u_{c A v} \\
(\%)\end{array}$} \\
\hline & & $\begin{array}{l}r_{01} \\
(\%)\end{array}$ & $\begin{array}{c}u(R)_{01} \\
(\%)\end{array}$ & $\begin{array}{l}u_{c 01} \\
(\%)\end{array}$ & $\begin{array}{l}R F_{1} \\
(\%)\end{array}$ & $\begin{array}{l}r_{02} \\
(\%)\end{array}$ & $\begin{array}{c}u(R)_{o 2} \\
(\%)\end{array}$ & $\begin{array}{l}u_{c 02} \\
(\%)\end{array}$ & $\begin{array}{l}R F_{3} \\
(\%)\end{array}$ & $\begin{array}{l}r_{03} \\
(\%)\end{array}$ & $\begin{array}{c}u(R)_{o 3} \\
(\%)\end{array}$ & $\begin{array}{l}u_{c 03} \\
(\%)\end{array}$ & \\
\hline Sulphadiazine & 89.0 & 5.2 & 3.2 & 6.1 & 81.5 & 1.7 & 5.3 & 5.6 & 78.8 & 2.9 & 6.1 & 6.8 & 6.2 \\
\hline Sulphathiazole & 74.0 & 5.4 & 7.5 & 9.2 & 71.8 & 1.1 & 8.1 & 8.2 & 65.8 & 2.6 & 9.9 & 10.2 & 9.3 \\
\hline Sulphapyridine & 88.3 & 4.6 & 3.4 & 5.7 & 82.3 & 1.5 & 5.1 & 5.3 & 79.7 & 3.0 & 5.9 & 6.6 & 5.9 \\
\hline Sulphamerazine & 89.2 & 5.0 & 3.1 & 5.9 & 84.5 & 2.2 & 4.5 & 5.0 & 80.7 & 3.6 & 5.6 & 6.6 & 5.9 \\
\hline Sulphamethazine & 89.8 & 4.2 & 2.9 & 5.1 & 83.7 & 1.2 & 4.7 & 4.9 & 82.2 & 3.2 & 5.1 & 6.1 & 5.4 \\
\hline Sulphamethizole & 76.3 & 5.2 & 6.8 & 8.6 & 73.0 & 2.1 & 7.8 & 8.1 & 63.3 & 4.6 & 10.6 & 11.5 & 9.5 \\
\hline S'methoxypyridazine & 80.3 & 5.7 & 5.7 & 8.1 & 79.0 & 1.4 & 6.1 & 6.2 & 75.7 & 4.0 & 7.0 & 8.1 & 7.5 \\
\hline
\end{tabular}


Table 8. Combined uncertainties by "bottom-up" and "top-down" approach. Top down 'method 1' used intra-laboratory reproducibility, 'method 2' used repeatability data from three occasions.

\begin{tabular}{lccc}
\hline & $\begin{array}{c}\mathbf{u}_{\mathbf{c}}(\boldsymbol{\%}) \\
\text { Bottom-up }\end{array}$ & $\begin{array}{c}\mathbf{u}_{\mathbf{c} \text { Av }}(\%) \\
\text { Top-down (method 1) }\end{array}$ & $\begin{array}{c}\mathbf{u}_{\mathbf{c} \text { Ave }}(\boldsymbol{\%}) \\
\text { Top-down (method 2) }\end{array}$ \\
\hline Sulphadiazine & 5.4 & 8.3 & 6.2 \\
Sulphathiazole & 8.8 & 12.0 & 9.3 \\
Sulphapyridine & 5.1 & 7.9 & 5.9 \\
Sulphamerazine & 5.3 & 8.3 & 5.9 \\
Sulphamethazine & 5.3 & 8.2 & 5.4 \\
Sulphamethizole & 9.0 & 12.5 & 9.5 \\
S'methoxypyridazine & 8.1 & 8.6 & 7.5 \\
\hline
\end{tabular}



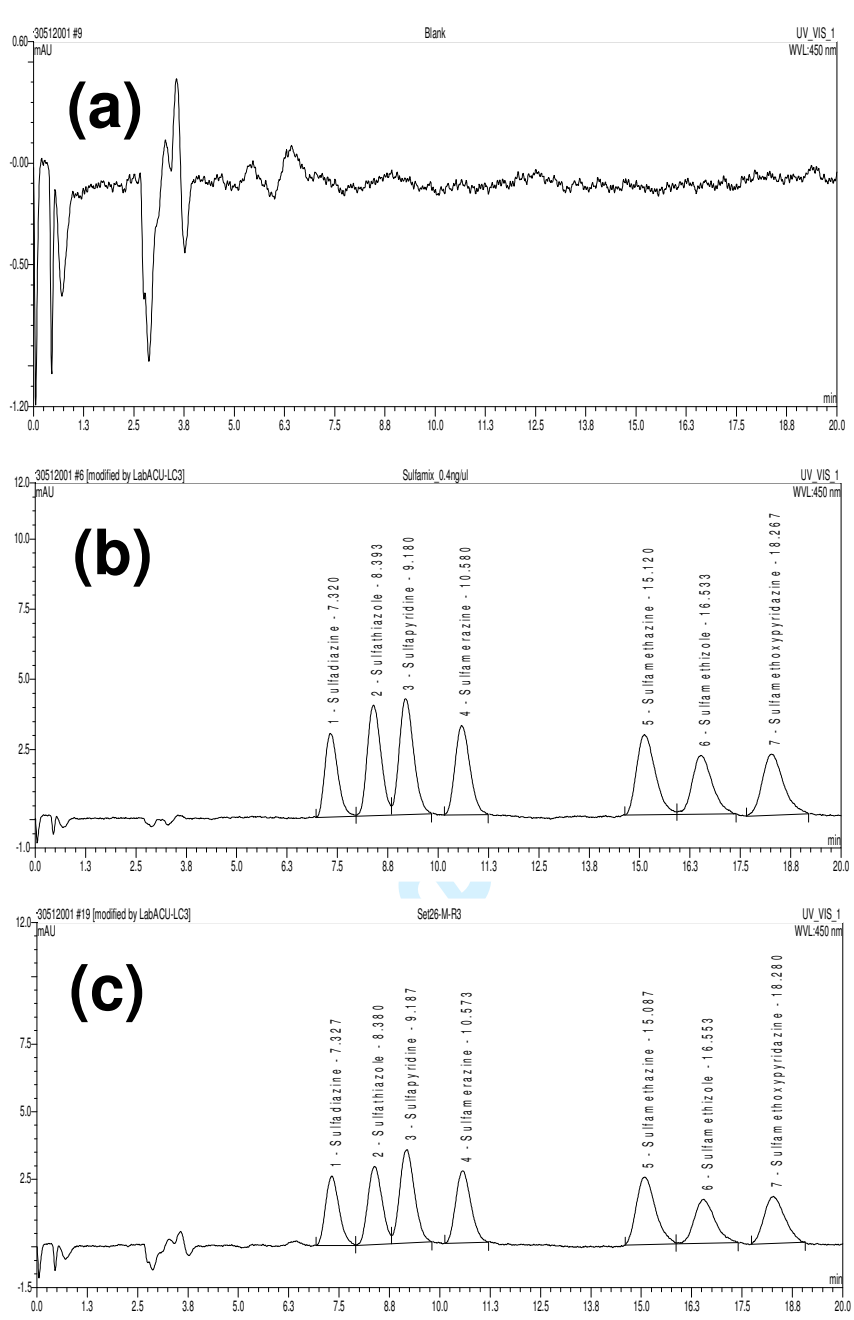

Figure 1. Typical HPLC-UV chromatograms for: (a), a negative kidney sample; (b), a mixed sulphonamide standard equivalent to $100 \mathrm{~g} \mathrm{~kg}^{-1}$ and (c), a negative kidney fortified at $100 \mu \mathrm{g} \mathrm{kg}^{-1}$. 


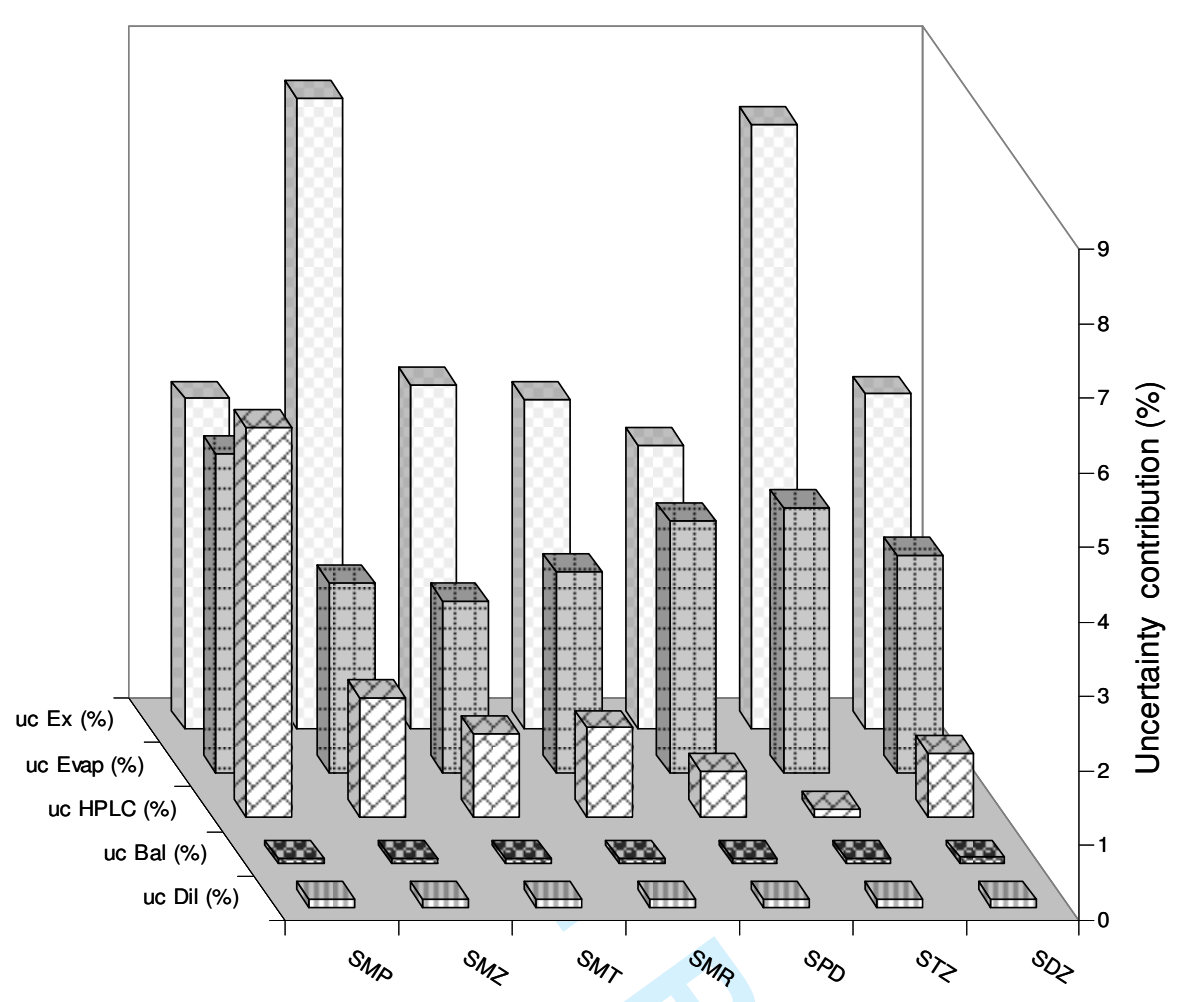

Figure 2. Contributions of the uncertainty of the different stages of the analytical method and other uncertainty sources to the overall uncertainty $(\mathrm{CV} \%)$. 